Relations industrielles

Industrial Relations

\title{
Session intensive en relations industrielles
}

Du 13 au 25 mai

Volume 1, numéro 8, avril 1946

URI : https://id.erudit.org/iderudit/1023946ar

DOI : https://doi.org/10.7202/1023946ar

Aller au sommaire du numéro

Éditeur(s)

Département des relations industrielles de l’Université Laval

\section{ISSN}

0034-379X (imprimé)

1703-8138 (numérique)

Découvrir la revue

Citer cet article

(1946). Session intensive en relations industrielles : du 13 au 25 mai. Relations industrielles / Industrial Relations, 1(8), 3-3. https://doi.org/10.7202/1023946ar

Tous droits réservés (C Département des relations industrielles de l’Université Laval, 1946
Ce document est protégé par la loi sur le droit d'auteur. L’utilisation des services d'Érudit (y compris la reproduction) est assujettie à sa politique d'utilisation que vous pouvez consulter en ligne.

https://apropos.erudit.org/fr/usagers/politique-dutilisation/ 


\section{- SESSION INTENSIVE EN RELATIONS INDUSTRIELLES}

\section{Du 13 au 25 mai}

Le Département des Relations industrielles de la Faculté des Sciences sociales de Laval a pour but de former des techniciens qui, à titre de directeurs de personnel, agents de relations industrielles, officiers de syndicats ou d'unions, secrétaires de comités paritaires ou fonctionnaires gouvernementaux, appliqueront la législation du travail et les lois de sécurité sociale. De là son enseignement universitaire spécialisé. Mais le rôle de notre Département ne se limite pas à l'enseignement universitaire. Dès les premières phases de son développement, le Département des Relations industrielles de Laval est entré en contact avec les associations ouvrières et patronales de la province. Ces contacts étaient nécessaires pour établir des liens indispensables entre l'Université et le monde des relations industrielles. D'ailleurs, notre Département a reçu de tous et de chacun une coopération très empressée et d'une valeur inestimable.

En juin dernier, le Département des Relations industrielles a organisé sa première session intensive à l'intention des officiers des syndicats et des unions, des directeurs de personnel et des contremaîtres, des secrétaires et des inspecteurs des comités paritaires et des fonctionnaires. Près de soixante-quinze personnes se sont inscrites à ces cours donnés par des spécialistes. A la suite du succès de cette première initiative et afin de répondre à de nombreuses demandes, il a été décidé qu'une session intensive aurait lieu chaque année. Notre deuxième session intensive en relations industrielles se tiendra, du 13 au 25 mai, à la Faculté des Sciences sociales, à Québec.

Les autorités du Département ont préparé, pour cette année, un programme entièrement différent de celui de l'an dernier. Les cours ont avant tout une portée pratique. L'actualité commande le choix des sujets ainsi qu'on peut le constater en lisant le programme. C'est dire que les personnes qui ont suivi les cours l'an dernier pourront s'inscrire de nouveau à cette seconde session intensive et en retirer de grands avantages. La session comprend quarante heures de cours. Un résumé de chaque cours sera distribué aux étudiants. Une brève période de discussion est également prévue après chaque cours, afin de permettre à ceux qui le désirent de soumettre des cas d'expérience. Voici le programme :

I - Morale sociale ;

II - La productivité du travail, source de richesses ;

III - Ảnalyse des tâches et rythme du travail ;

IV - Le rôle des commissions d'apprentissage ;

V - Tendances du syndicalisme ouvrier ;

VI - Tendances du syndicalisme patronal ;

VII — Liberté syndicale ;

VIII - Clauses de sécurité syndicale ;

IX - Conciliation et arbitrage ;

$\mathrm{X}$ - Convention collective ;

$\mathrm{XT}$ - La sélection du personnel ;

XII - La permutation du personnel ;

XIII - Hygiène industrielle ;

XIV - La direction du personnel et la sécurité ;

XV - Les problèmes de sécurité et l'avenir ;
XVI - Les caisses de prestations ;

XVII - Les accidents de travail ;

XVIII - L'assurance-chômage ;

XIX - Le bien-être social.

Les professeurs dont les noms suivent figurent au programme : le T. R. P. Georges-Henri Lévesqueł o. P., doyen de la Faculté des Sciences sociales ; M. Gérard Tremblay, sous-ministre du Travail ; R. P. Gonzalve Poulin o. F. M., directeur des études à la Faculté des Sciences sociales ; M.J. O'Connell-Maher, sous-ministre adjoint du Travail ; M. Jean-Pierre Després, directeur des services au ministère du Travail ; $M$. Bertrand Boissonnault, ingénieur et directeur des relations industrielles à la Dominion Textile Co. ; $M$. Léonce Girard, secrétaire du comité paritaire de l'industrie de la chaussure ; M. Gérard Dion, ptre, secrétaire de l'Office des recherches industrielles de Laval; $D r$ Wilfrid LeBlond, professeur d'hygiène sociale et industrielle à la Faculté des Sciences sociales de Laval ; $M$. Georges Lafrance, surintendant des assurances; $M . F . T$. Hecker, secrétaire de la Commission des accidents du travail ; M. S. Picard. gérant de la Commission d'Assurance-Chômage à Québec ; $M$. Donat Quimper, directeur du Service de conciliation et d'arbitrage, district de Québec.

Pour toute autre information, s'adresser au secrétaire du Département des Relations industrielles, Faculté des Sciences sociales, Université Laval, Québec. (téléphone : 6517). Demandez le prospectus complet de la session.

\section{L'OUVRIER ET SON SYNDICAT}

(Suite de la page 1)

ment d'étudier et de discuter des propositions susceptibles d'accroître leur rendement à l'usine ou d'apporter une contribution positive au patron qui les emploie.

Nous invitons les travailleurs à réfléchir sérieusement sur les points que nous venons de soulever. Le syndicalisme ne doit pas seulement rendre les travailleurs libres mais aussi les rendre meilleurs dans leur vie privée et à l'usine.

\section{THE WORKER AND HIS UNION}

(From page 1)

diately preceding wage demands than any regular meeting to which they are convened to discuss rropositions likely to increase their efficiency at the plant or yield a positive contribution to their employer.

Therefore, we invite all workers to honestly consider the questions we have just brought up. Syndicalism must not only make workers free, it must also be conducive to their betterment at home and at the plant. 